Chapter 6

\title{
Fabrication and Characterization of Metal-Loaded Mixed Metal Oxides Gas Sensors for the Detection of Hazardous Gases
}

\author{
Chang-Seop Lee and Yong Jae Kim \\ Additional information is available at the end of the chapter
}

http://dx.doi.org/10.5772/intechopen.68414

\begin{abstract}
This study concerns gas sensors that may protect individuals by detecting hazardous gases that may be generated in hot spaces $\left(\geq 50^{\circ} \mathrm{C}\right)$ with residues of organic waste. We investigated the responses and selectivities of the sensors to different kinds of hazardous gases such as acetaldehyde, toluene and hydrogen sulfide. We also investigated operating temperatures and catalysts for the sensors. The thick film semiconductor sensors that detected some hazardous gases were prepared using nano-sized sensing material powders $\left(\mathrm{SnO}_{2}, \mathrm{WO}_{3}, \mathrm{ZnO}\right)$ that were prepared through sol-gel and precipitation methods. The nano-sized sensing materials were blended with various amounts of metal oxides $\left(\mathrm{SnO}_{2}, \mathrm{ZnO}, \mathrm{WO}_{3}\right)$ and coated with transition metals ( $\mathrm{Pt}, \mathrm{Pd}, \mathrm{Ru}, \mathrm{Au}, \mathrm{Ag}, \mathrm{Cu}$ and In). The metal oxide thick films were fabricated on an $\mathrm{Al}_{2} \mathrm{O}_{3}$ plate with a Ni-Cr heater and a $\mathrm{Pt}$ electrode through a screen-printing method. Morphologies, compositions, phases, surface areas and particle sizes of sensor compounds were examined by SEM, EDS, XRD and BET analysis. The investigated response to the various hazardous vapors was expressed as the value of $\mathrm{Ra} / \mathrm{Rg}$, where $\mathrm{Ra}$ and $\mathrm{Rg}$ are the resistance of the sensor material in the air and in hazardous gas, respectively.
\end{abstract}

Keywords: gas sensors, hazardous gas, metal oxide, screen-printing, sol-gel, thick film

\section{Introduction}

The semiconducting metal oxide gas sensors currently constitute one of the most investigated groups of gas sensors. Semiconducting metal oxide gas sensors are electrical conductivity sensors with active sensing layers that exhibit resistance changes when coming into contact with the hazardous gas under investigation. Metal oxide gas sensors are appropriate for a 
wide range of applications and for the detection of all reactive gases due to unique atomiclevel chemistry and properties of each device.

Hydrocarbons, nitrogen oxides, oxidized hydrocarbons and sulfur oxides are common air contaminants in everyday life. Of these chemicals, hazardous gases produced from organic solvents used in industrial and laboratory processes are becoming an area of increasing social concern, since those vapors have a direct damage on the human body. Acute and chronic exposures to hazardous gases may cause humans to develop central nervous system disorders, reproductive system diseases and leukemia [1-3].

Formaldehyde and acetaldehyde are known to be two of the carbonyl compounds most widely disseminated in ambient air. Aldehydes products produced by combustion and oxidation can interact directly with ozone. The products are major components of smog, and further photochemical reactions may enhance global warming by destroying ozone layer in the stratosphere. Aldehydes commonly present in the gaseous state at $25^{\circ} \mathrm{C}$ and stay in the air for a long period of time. Acetaldehyde is the main component of hazardous vapor produced in newly built houses and can pollute the air both outdoors and indoors. Humans exposed to aldehydes irritations to their respiratory systems such as their throats, noses and bronchi. In addition, acetaldehyde may affect the central nervous system of an individual via anesthesia. Extreme physical reactions such as paralysis, respiratory disorders, and even the onset of a comatose state are among the events that can occur in extreme cases of acetaldehyde exposure $[4,5]$. Therefore, for both environmental and for health reasons, it is very important to detect the presence of aldehydes.

Hydrogen sulfide, a byproduct of the active decomposition of organic matter, is very hazardous gas. For instance, many people died in the underground sewage systems of Paris during the French Revolution. According to the U.S. government report, $\mathrm{H}_{2} \mathrm{~S}$ is a watchful gas for instant death in the working place. Because $\mathrm{H}_{2} \mathrm{~S}$ gas is rapidly oxidized into sulfides that can easily be eliminated via the kidneys, the gas is not known to have a cumulative toxic effect. Inhalation of lethal concentrations (1000-2000 ppm) of hydrogen sulfide may cause olfactory fatigue or paralysis and ultimately the cessation of breath. Other forms of respiratory distress known to occur after inhalation of hydrogen sulfide (500-1000 ppm) are dose-dependent deficits such as hyperpnea (via carotid body stimulation) and sleep apnea. Low levels of hydrogen sulfide (50-500 ppm) can act as primary irritants to the eyes and the respiratory system. Continuous exposure to 250-600 ppm of the hazardous gas may result in pulmonary edema.

Toluene is a colorless volatile liquid with a unique smell. Safe handling of this highly volatile compound includes storage in a perfectly sealed container. If toluene is handled in an industrial workplace or in a laboratory without wearing special protective equipment, a worker or researcher may inhale $100 \%$ of the toluene. Prolonged inhalation exposure to toluene, even at low concentrations, can lead to deterioration of lung function and eyesight. Additional effects include a headache, paralysis of the hands/feet, cancer, leukemia, mental derangement, malignant lymphoma and depression of central nervous system.

In this chapter, we describe the development of catalyst-loaded metal oxide gas sensors to detect gases that posed hazards to the human body, that is, acetaldehyde gas, hydrogen sulfide and toluene vapors. 


\section{Experimental details}

\subsection{Preparation of sensor materials}

One of the disadvantages of gas sensors is the costly requirement for more electricity to maintain a high operating temperature. To mitigate this disadvantage, there is a need to increase the electronic conductivity of the sensor materials in order to decrease the operating temperature. One way to improve the electronic conductivity is to add conducting materials to sensor materials.

For the acetaldehyde gas sensor, we synthesized $\mathrm{WO}_{3}$ through a sol-gel process and used it as a sensing material to detect acetaldehyde gas. Metal catalysts were added through the impregnation method [4-6], to enhance the sensitivity and selectivity that are functional prerequisites of the gas sensor. Transition metals ( $\mathrm{Pd}, \mathrm{Ru}, \mathrm{Pt}$ and $\mathrm{In}$ ) were weighed to give weight ratios of 1-5 $\mathrm{wt} \%$, and $1 \mathrm{ml}$ of hydrochloric acid $(\mathrm{HCl})$ diluted with distilled water was added to completely dissolve the metal catalysts in a beaker. Heating and stirring of appropriate suspensions with magnetic stirrers yielded $\mathrm{WO}_{3}$ or $\mathrm{SnO}_{2} / \mathrm{WO}_{3}$ powders impregnated with metal catalysts. Then, we dried each solution for $12 \mathrm{~h}$ at $100^{\circ} \mathrm{C}$ and calcined it for $2 \mathrm{~h}$ at $500^{\circ} \mathrm{C}$ to get powder. Finally, we obtained a fine powder of the sensing material by crushing the crude material.

We added metal catalysts to $\mathrm{WO}_{3} / \mathrm{SnO}_{2}$ powder to prepare the sensing material by using the same methods described above in the case of the hydrogen sulfide sensor. Additional techniques included co-precipitation, impregnation method and alleged fabrication [6]. We put various metals of $\mathrm{Pd}, \mathrm{Ru}, \mathrm{Ag}, \mathrm{Au}$ and In as catalysts in the flask with the ratios of $0.5-5 \mathrm{wt} \%$ and dissolved the metal catalysts by adding $1 \mathrm{ml}$ of concentrated $\mathrm{HCl}$ solution. We then added $\mathrm{SnO}_{2} / \mathrm{WO}_{3}$ powder to impregnate the metal catalysts. These materials were slowly heated while stirring with a magnetic stirrer for an effective loading of metal catalysts to $\mathrm{SnO}_{2} / \mathrm{WO}_{3}$. The as-prepared sample was then dried for $24 \mathrm{~h}$ at $110^{\circ} \mathrm{C}$ and calcinated for $2 \mathrm{~h}$ at $600^{\circ} \mathrm{C}$. Finally, the sample was pulverized to make each one of the sensor materials.

In the case of the toluene sensor, we produced a sensor material by adding carbon black using an impregnation method. An impregnation method was also used for the addition of the transition metal. Carbon black was measured to be at $1-20 \mathrm{wt} . \%$ of the main material. Then, it was put into a beaker and $2 \mathrm{ml}$ of $\mathrm{HCl}$ was added. After transition metal and carbon black are completely dissolved, distilled water was added to make a homogeneous solution. Next, the transition metal and carbon black were impregnated by adding $\mathrm{SnO}_{2} / \mathrm{ZnO}$ powder. Then, it was gradually heated while stirring with a magnetic stirrer to produce $\mathrm{SnO}_{2} / \mathrm{ZnO} /$ catalyst powder with carbon black deposit. The powder was dried for $24 \mathrm{~h}$ at $110^{\circ} \mathrm{C}$ and went through calcination for $5 \mathrm{~h}$ at $600^{\circ} \mathrm{C}$. The desired material was obtained by crushing the obtained powder [7-11].

\subsection{Fabrication of thick film}

A commercial product which has Pt electrode at $0.5-\mathrm{mm}$ interval and a $\mathrm{Ni}-\mathrm{Cr}$ heater in a $10 \mathrm{~mm} \times 8 \mathrm{~mm} \times 0.65 \mathrm{~mm} \mathrm{Al}_{2} \mathrm{O}_{3}$ base plate was used as the supporting material for the sensor. The plate went through a washing process using an acetone and heat treatment process at $300^{\circ} \mathrm{C}$ for $1 \mathrm{~h}$ in order to remove contaminants before fabrication of the thick film. Next, 


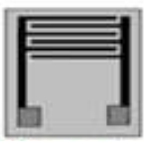

Electrode

Top

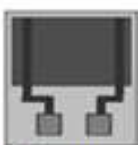

Heater

Bottom

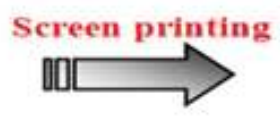

Figure 1. Structure of thick film sensor.

\section{Catalyst/Sensing materials thick film}

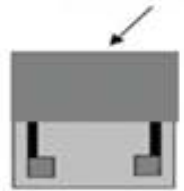

Top view

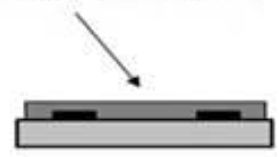

Side view

the sensor material paste was coated by a screen-printing method at a thickness of 20-60 $\mu \mathrm{m}$. Figure 1 shows diagrams before and after coating of the thick films [12].

Regarding thick film formation on each sensor material, a paste with proper viscosity was screen-printed on an alumina base plate with electrode formation achieved by adding ethylene glycol as a binder at 15-30 wt.\% of powder. The resulting thick film element was left at room temperature for $12 \mathrm{~h}$. Then, it was dried for $24 \mathrm{~h}$ in an $110^{\circ} \mathrm{C}$ oven. After $2 \mathrm{~h}$ calcination at $600^{\circ} \mathrm{C}$, the final product was obtained.

\subsection{Analysis of sensitivity characteristics}

After we had installed the gas sensor at a distance of $50 \mathrm{~mm}$ from the bottom of a $10 \mathrm{~L}(250 \mathrm{~mm}$ $x 200 \mathrm{~mm} \times 200 \mathrm{~mm}$ ) chamber, the sensitivity of the gas sensor was measured with the temperature range from 200 to $400^{\circ} \mathrm{C}$. A stabilization procedure was performed for $12 \mathrm{~h}$ in the

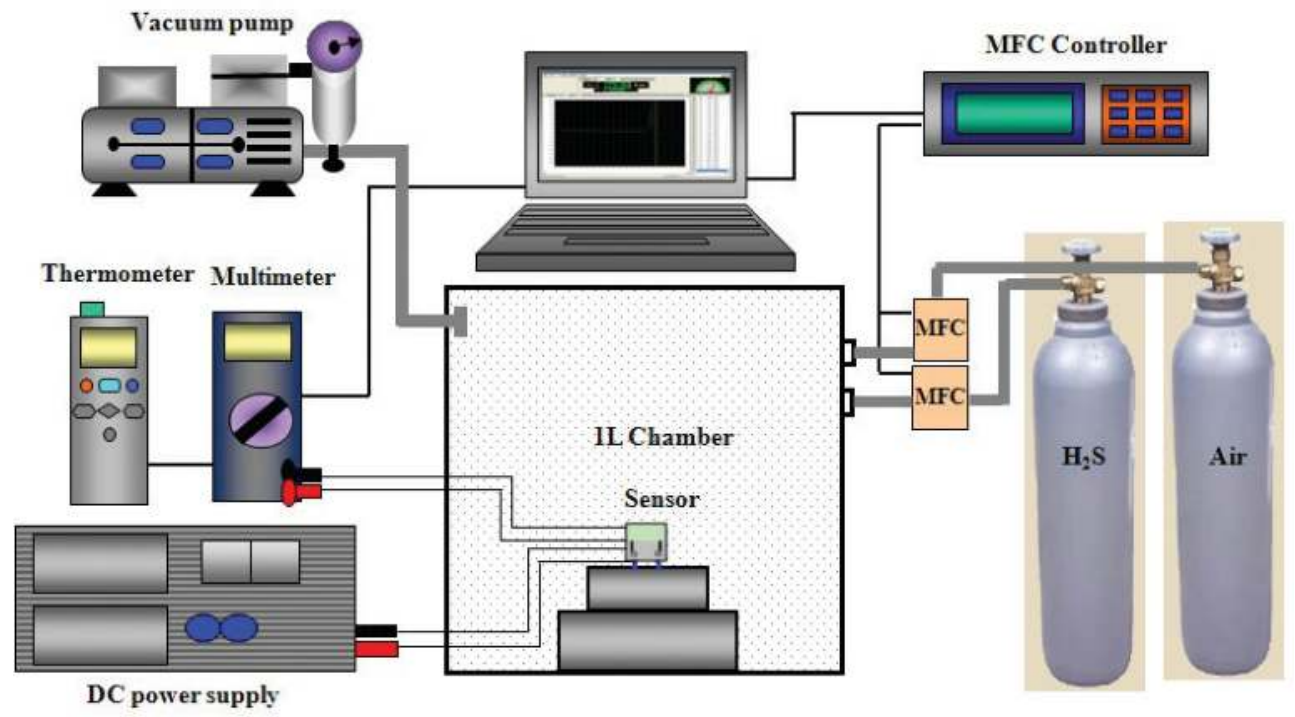

Figure 2. Apparatus used for gas-sensing experiments. 
same temperature range to remove the electrons from the system. Then, the target gas had been dispersed using a fan in the chamber. When the equilibrium concentration was reached, the resistance was measured with an electrometer. The sensor sensitivity was expressed as the value of $\mathrm{Ra} / \mathrm{Rg}$, where $\mathrm{Ra}$ and $\mathrm{Rg}$ are the resistance of the sensor material in the air and in target gas, respectively. The experimental apparatus is shown in Figure 2.

\section{Results and discussion}

\subsection{Analysis results of sensing materials used for the gas sensor}

\subsubsection{The acetaldehyde gas sensor}

In this study, we prepared sensing materials for a gas-detecting sensor using various composition ratios of $\mathrm{WO}_{3}$ powder employed as the main sensing element to metal oxide $\left(\mathrm{SnO}_{2}\right)$ and metal catalysts. XRD, SEM/EDS and BET methods were employed to characterize the crystallinity and morphology, phase, composition and specific surface areas. The XRD patterns of $\mathrm{WO}_{3}$ at various calcination temperatures and those when $\mathrm{SnO}_{2}$ and metal catalysts were added to $\mathrm{WO}_{3}$ were shown in Figures 3 and 4, respectively. In Figure 3, the peak intensity of $\mathrm{WO}_{3^{\prime}}$, which is a characteristic of crystallization, rises with increasing calcination temperatures. This means that the crystallinity is enhanced at higher calcination temperature. By comparing the data we obtained with those of JCPDS as reference data, we concluded that the experimental data were agreed with an orthorhombic structure, which is one of the possible structures of $\mathrm{WO}_{3}$ [13]. In Figure 4, new peaks started to appear at characteristic $2 \theta$ values as metal catalysts and metal oxides were added.

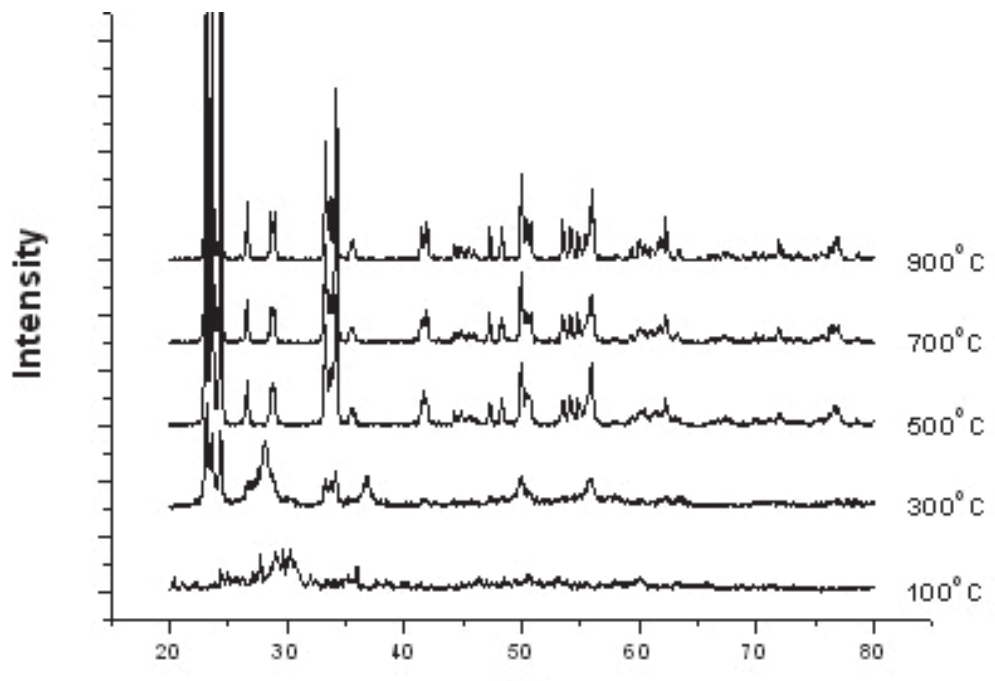

$2 \theta$

Figure 3. X-ray diffraction patterns of $\mathrm{WO}_{3}$ powder with temperature. 


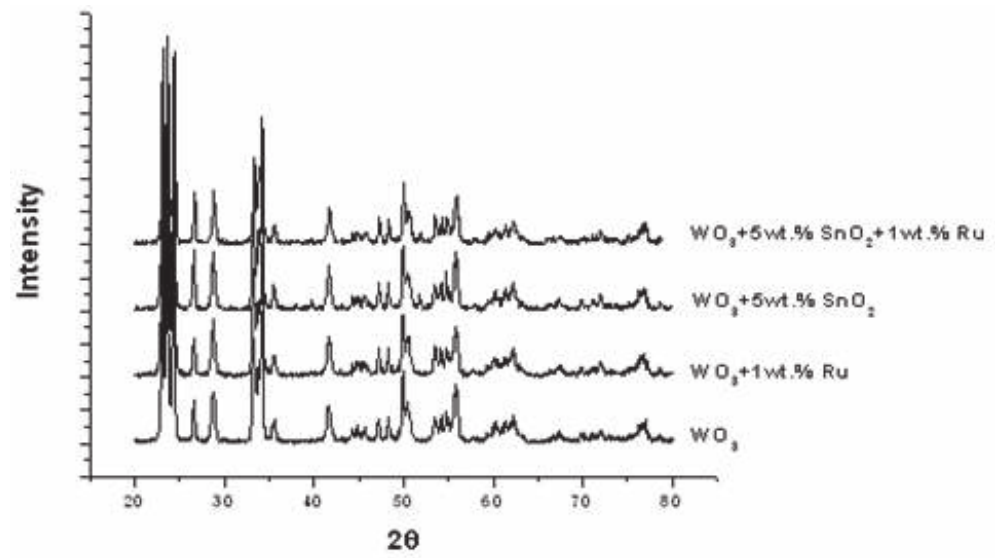

Figure 4. X-ray diffraction patterns of the various sensor materials based on catalyst $/ \mathrm{SnO}_{2} / \mathrm{WO}_{3}$.
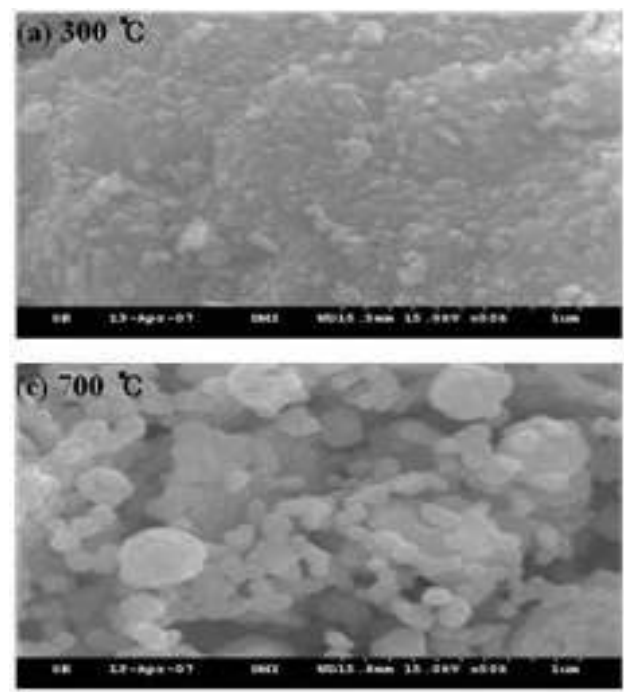
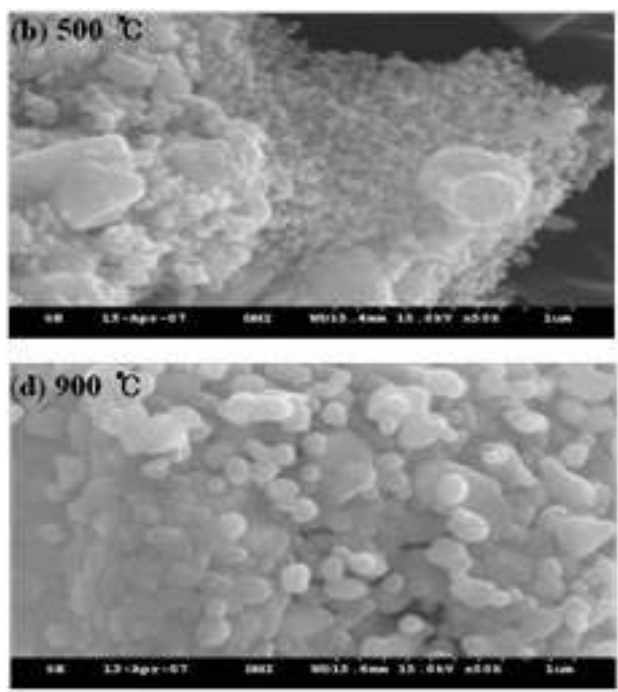

Figure 5. SEM image of WO3 powders calcined for $2 \mathrm{~h}$ at (a) $300^{\circ} \mathrm{C}$, (b) $500^{\circ} \mathrm{C}$, (c) $700^{\circ} \mathrm{C}$ and (d) $900^{\circ} \mathrm{C}$.

Figure 5 exhibits SEM images of the $\mathrm{WO}_{3}$ thick film at various calcination temperatures. These SEM images show that the particle size of the $\mathrm{WO}_{3}$ thick film increases with rising calcination temperatures.

Figure 6 represents SEM images and EDS results of each sensing material composed of $\mathrm{WO}_{3}$ containing metal oxides and metal catalysts. Figure 6a shows SEM photos and EDS results for sensor material of $\mathrm{WO}_{3}$ only. Figure 6(b), (c), and (d) shows SEM photos and EDS data for sensor materials of $5 \mathrm{wt} \% \mathrm{SnO}_{2} / \mathrm{WO}_{3^{\prime}} 1 \mathrm{wt} \% \mathrm{Ru} / \mathrm{WO}_{3^{\prime}}$, and $1 \mathrm{wt} \% \mathrm{Ru} / 5 \mathrm{wt} \%$ $\mathrm{SnO}_{2} / \mathrm{WO}_{3}$, respectively. The SEM photos obviously show the surface morphology of each 
sensor material. The EDS data indicate the appearance of new peaks of the component in each sensor material.

\subsubsection{The $\mathrm{H}_{2} \mathrm{~S}$ gas sensor}

A sensing material for gas detection was fabricated with various mixing ratios of the main material $\mathrm{SnO}_{2}$, metal oxide and catalyst. The techniques of SEM, EDS, XRD and BET were employed to analyze surface morphology, component, the degree of crystallinity, phase and surface area of each fabricated sensing material. Figure 7 shows the XRD patterns of the $\mathrm{SnO}_{2}$ synthesized by sol-gel method and $\mathrm{SnO}_{2}$ mixed with catalyst and metal oxide.

By a comparison of the data of $\mathrm{SnO}_{2}$ we obtained in this experiment with those in JCPDS, we presume the structure to be rutile form which is shown in Figure 7. As for the sample of $\mathrm{SnO}_{2}$ mixed with $10 \mathrm{wt} \% \mathrm{WO}_{3^{\prime}}$ a new peak was appeared around $2 \theta$. Referring to the data in JCPDS, the data of $\mathrm{WO}_{3}$ tell us that the structure is orthorhombic among the three possible structures. Based on the interpretation of peaks of $\mathrm{SnO}_{2}$, we can say that there was no specific phase change. Any new $2 \theta$ value was not also observed in the diffraction pattern for the sample of $\mathrm{SnO}_{2}$ mixed with $10 \mathrm{wt} \% \mathrm{WO}_{3} / 1 \mathrm{wt} \% \mathrm{Ru}$. This implies that $1 \mathrm{wt} \%$ of $\mathrm{Ru}$ was not sufficient to produce a crystalline peak of $\mathrm{Ru}$.

Table 1 shows the measured results of specific surface areas of $\mathrm{SnO}_{2}$ in which pure $\mathrm{SnO}_{2}$ was mixed with $10 \mathrm{wt} \% \mathrm{WO}_{3}$ and various metal catalysts. Compared to pure $\mathrm{SnO}_{2}, \mathrm{SnO}_{2}$ with added $10 \mathrm{wt} \% \mathrm{WO}_{3}$ and various metal catalysts showed larger BET surface areas, pore diameters and pore volumes. This means that $\mathrm{SnO}_{2}$ added with $\mathrm{WO}_{3}$ and metal catalyst hindered the particle growth, which results in increasing the specific surface area.

In particular, the $\mathrm{SnO}_{2}$ powder (in which $10 \mathrm{wt} \% \mathrm{WO}_{3}$ was mixed with $1 \mathrm{wt} \% \mathrm{Ru}$ ) showed the highest BET specific surface area, pore diameter and total pore volume. The sensor fabricated with this material showed good functional properties, including response, reaction, recovery and selectivity.

SEM photos and EDS data for $\mathrm{SnO}_{2}$ powder added with $\mathrm{WO}_{3}$ and various metals were shown in Figure 8. In SEM photos, the surface morphology of each sensing material could be observed, and the peak of the component element for each sensing material was verified by the EDS data.

\subsubsection{The toluene gas sensor}

This study produced sensor material for gas detection by varying the mixing ratios of $\mathrm{SnO}_{2}$ powder as main material, $\mathrm{ZnO}$, transition metal catalyst and carbon black. The crystal property of each produced sensor material was analyzed by using XRD measurements. Figure 9 shows each XRD pattern of various sensor materials such as $\mathrm{SnO}_{2}$ synthesized by the precipitation method, $\mathrm{SnO}_{2} / \mathrm{ZnO}$ which is $\mathrm{SnO}_{2}$ with $20 \mathrm{wt}$. $\% \mathrm{ZnO}, \mathrm{SnO}_{2} / \mathrm{ZnO} / \mathrm{Cu}$ which is $\mathrm{SnO}_{2} / \mathrm{ZnO}$ added of 1 wt. $\% \mathrm{Cu}$ and $\mathrm{SnO}_{2} / \mathrm{ZnO} / \mathrm{Cu} /$ carbon black which is $\mathrm{SnO}_{2} / \mathrm{ZnO} / \mathrm{Cu}$ added of 5 wt.\% carbon black. When the experimental data were compared to various values of $\mathrm{SnO}_{2}$ and $\mathrm{ZnO}$ in JCPDS, it was confirmed that the peaks were characteristic of the crystal structure held by $\mathrm{SnO}_{2}$ and $\mathrm{ZnO}$. Meanwhile, it was not possible to confirm the peak of $\mathrm{Cu}$ and carbon black. The XRD 

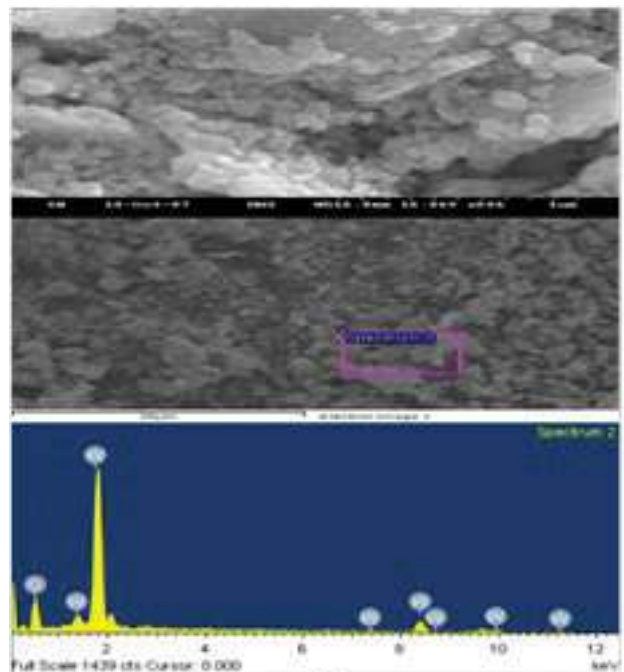

(a)
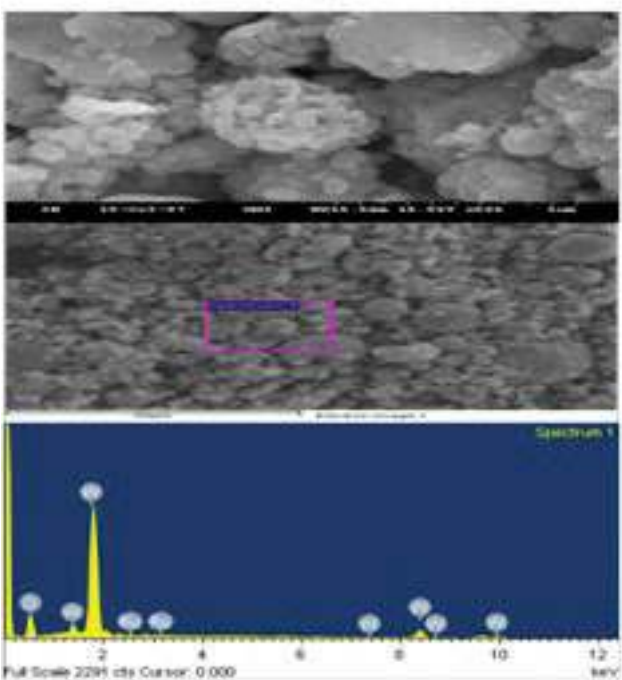

(c)
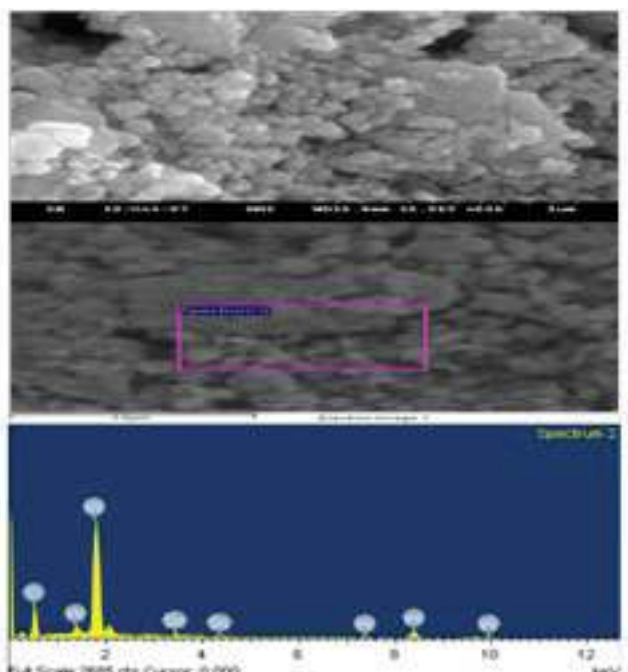

(b)
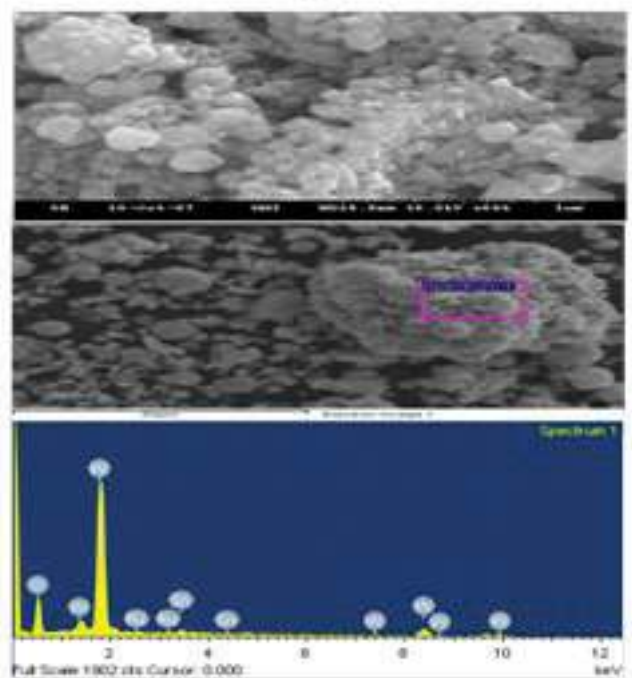

(d)

Figure 6. SEM images and EDS results of sensing materials. Upper: SEM ( $\times 50 \mathrm{~K})$, middle: SEM (5 K) and lower: EDS ( $\times 5 \mathrm{~K})$.

peak for $\mathrm{Cu}$ was not available because only small amount of $\mathrm{Cu}$ at $1 \mathrm{wt}$.\% was added. The XRD peak for carbon black was not available because carbon black is a weak crystalline material.

Figure 10 shows SEM images taken at 100,000 magnification showing ratios of $\mathrm{SnO}_{2^{\prime}}$ $\mathrm{SnO}_{2} / 20 \% \mathrm{ZnO}, \mathrm{SnO}_{2} / 20 \% \mathrm{ZnO} / 1 \% \mathrm{Cu}$ and $\mathrm{SnO}_{2} / 20 \% \mathrm{ZnO} / 1 \% \mathrm{Cu} / 5 \%$ carbon black, respectively. 


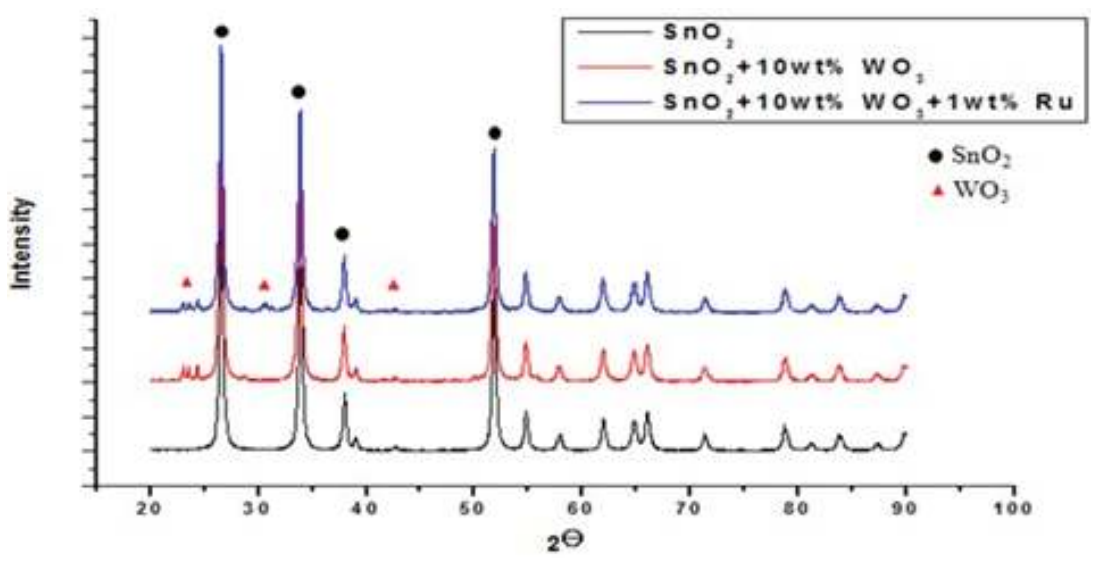

Figure 7. XRD patterns of catalyst $/ \mathrm{WO}_{3} / \mathrm{SnO}_{2}$ powder.

\begin{tabular}{llll}
\hline Samples & BET surface area $\left(\mathrm{m}^{2} / \mathrm{g}\right)$ & Pore diameter $(\mathbf{n m})$ & Total pore volume $\left(\mathrm{cm}^{3} / \mathrm{g}\right)$ \\
\hline $\mathrm{SnO}_{2}$ & 7.16 & 12.3 & 0.1218 \\
$1 \mathrm{wt} \% \mathrm{Ru}-10 \mathrm{wt} \% \mathrm{WO}_{3} / \mathrm{SnO}_{2}$ & 13.06 & 31.6 & 0.1398 \\
$1 \mathrm{wt} \% \mathrm{Pd}-10 \mathrm{wt} \% \mathrm{WO}_{3} / \mathrm{SnO}_{2}$ & 10.73 & 3.795 & 0.09435 \\
$1 \mathrm{wt} \% \mathrm{Au}-10 \mathrm{wt} \% \mathrm{WO}_{3} / \mathrm{SnO}_{2}$ & 10.64 & 21.01 & 0.09975 \\
$1 \mathrm{wt} \% \mathrm{In}-10 \mathrm{wt} \% \mathrm{WO}_{3} / \mathrm{SnO}_{2}$ & 11.53 & 26.92 & 0.1202 \\
$1 \mathrm{wt} \% \mathrm{Ag}-10 \mathrm{wt} \% \mathrm{WO}_{3} / \mathrm{SnO}_{2}$ & 11.39 & 22.34 & 0.09927 \\
\hline
\end{tabular}

Table 1. Surface area $\left(\mathrm{m}^{2} / \mathrm{g}\right)$, pore diameter $(\mathrm{nm})$, pore volume $\left(\mathrm{cm}^{3} / \mathrm{g}\right)$ of catalysts $/ \mathrm{WO}_{3} / \mathrm{SnO}_{2}$.
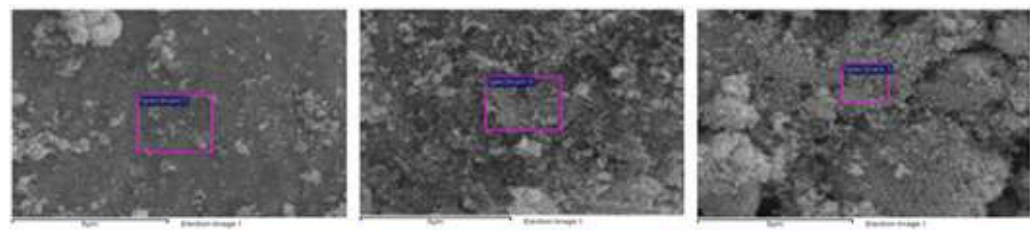

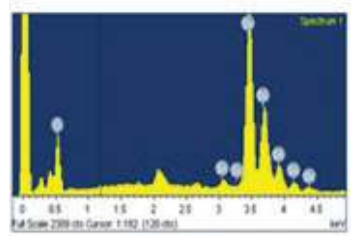

(a) $\mathrm{SnO}_{2}$

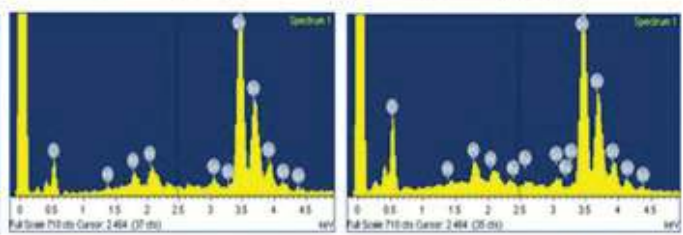

(b) $\mathrm{SnO}_{2}+\mathrm{WO}_{3}$

(c) $\mathrm{SnO}_{2}+\mathrm{WO}_{3}+\mathrm{Ru}$

Figure 8. SEM images and EDS results of gas-sensing materials. (a) $\mathrm{SnO}_{2^{\prime}}$ (b) $10 \mathrm{wt} \% \mathrm{WO}_{3} / \mathrm{SnO}_{2}$ and (c) $1 \mathrm{wt} \% \mathrm{Ru} / 10$ $\mathrm{wt} \% \mathrm{WO}_{3} / \mathrm{SnO}_{2}$. 


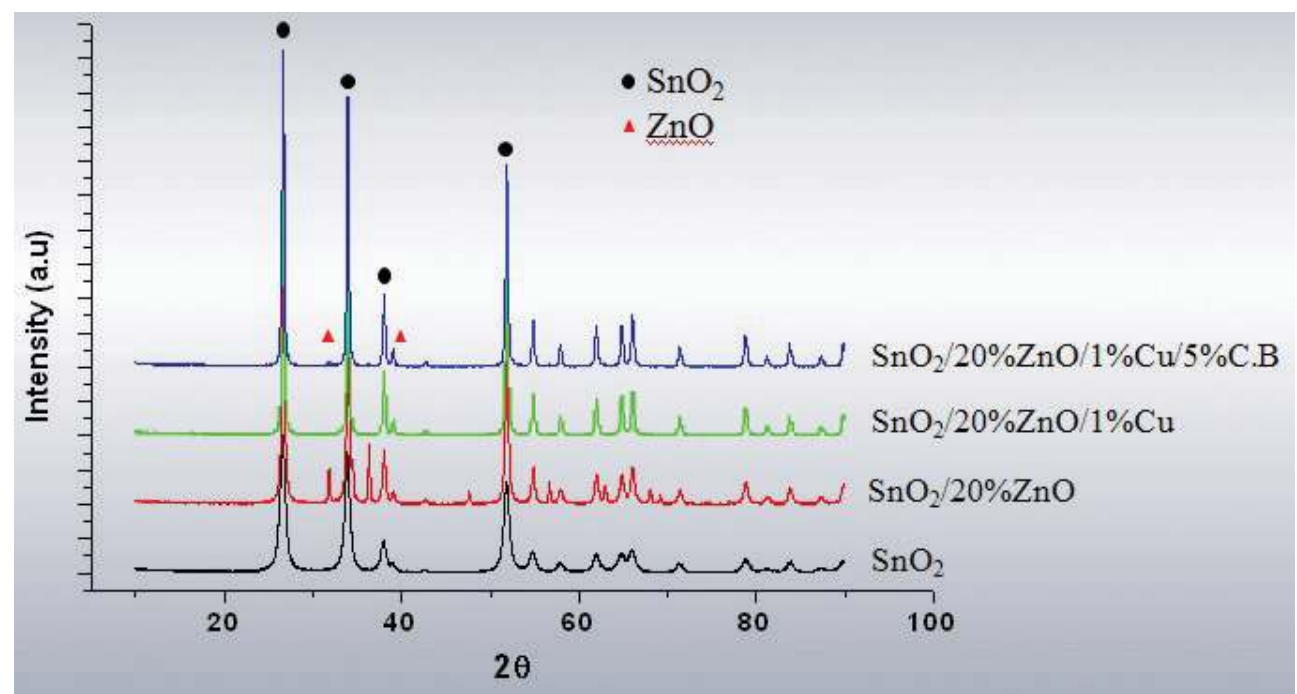

Figure 9. XRD patterns of the various sensor materials.
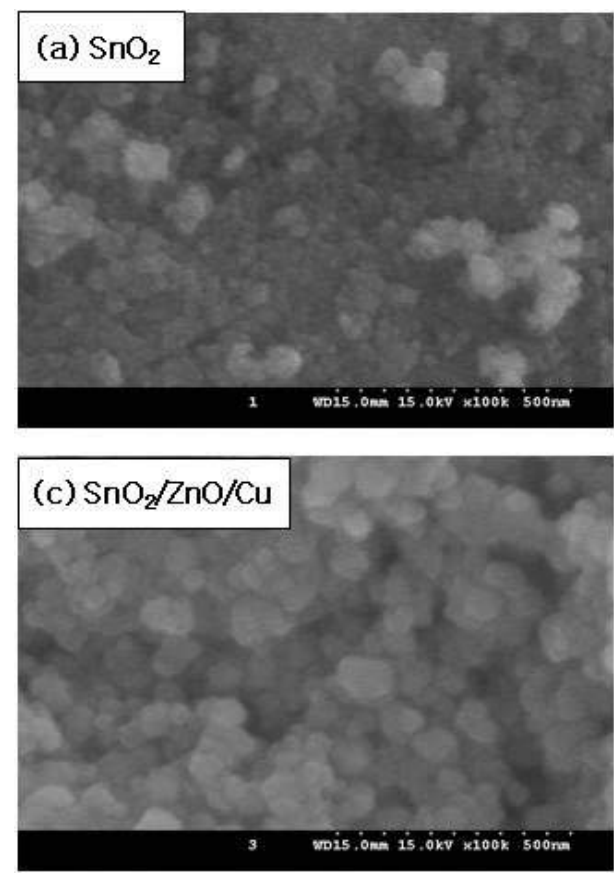

Figure 10. SEM images of the various sensor materials.

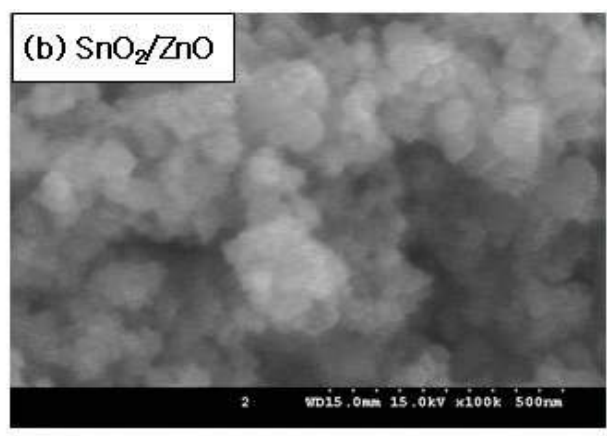

(d) $\mathrm{SnO}_{2} / \mathrm{ZnO} / \mathrm{Cu} /$ carbon black

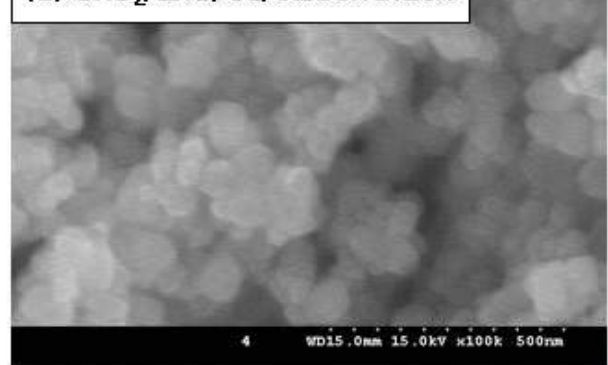


From theseSEMimages, itcould be seen that the sensor material made of $\mathrm{SnO}_{2} / 20 \% \mathrm{ZnO} / 1 \% \mathrm{Cu} / 5 \%$ carbon black had uniform particle sizes and crystallinities compared to other sensor materials.

Figure 11 shows the SEM images and EDS measurements for each sensor material composed of $\mathrm{SnO}_{2}, \mathrm{SnO}_{2} / 20 \% \mathrm{ZnO}, \mathrm{SnO}_{2} / 20 \% \mathrm{ZnO} / 1 \% \mathrm{Cu}$ and $\mathrm{SnO}_{2} / 20 \% \mathrm{ZnO} / 1 \% \mathrm{Cu} / 5 \%$ carbon black, respectively. It was possible to observe the surface state of each sensor material through studying the SEM images shown in Figure 11. It was also possible to confirm the peaks of component elements existing in each sensor material from the EDS results. The existence of $\mathrm{Sn}$ and $\mathrm{O}$ was confirmed in Figure 11(a); the existence of $\mathrm{Sn}, \mathrm{O}$ and $\mathrm{Zn}$ was confirmed in Figure 11(b); the existence of $\mathrm{Sn}, \mathrm{O}, \mathrm{Zn}$ and $\mathrm{Cu}$ was confirmed in Figure 11(c) and the existence of $\mathrm{Sn}, \mathrm{O}, \mathrm{Zn}, \mathrm{Cu}$ and $\mathrm{C}$ was confirmed in Figure 11(d).

\subsection{Response characteristics to acetaldehyde gas}

Figure 12 shows the sensing characteristics of $\mathrm{WO}_{3}$ thick film sensor to acetaldehyde (100 ppm) at the various operating and calcination temperatures. In particular, $\mathrm{WO}_{3}$ calcined at $500^{\circ} \mathrm{C}$ is shown to give the best sensitivity at $350^{\circ} \mathrm{C}$. The sensing characteristics of the sensor after addition of $\mathrm{SnO}_{2}$ and metal catalyst to acetaldehyde gas (100 ppm) at various operating temperatures were shown in Figure 13. While the highest sensitivity was reached at $350^{\circ} \mathrm{C}$ in the case of $\mathrm{WO}_{3}$ alone, this sensitivity peak occurred at $300^{\circ} \mathrm{C}$ in the presence of additional constituents, that is, $\mathrm{SnO}_{2}$ and $\mathrm{Ru}$. This can be understood as follows: at a given temperature, the activation energy changes greatly depending on the amount of $\mathrm{SnO}_{2}$ and the kind of metal catalyst added. Because the sensitivity of a sensor degrades with the temperature higher than $300^{\circ} \mathrm{C}$, the experiments were carried out at a fixed operation temperature of $300^{\circ} \mathrm{C}$.

Metal catalysts were added to the sensor material in order to improve the sensitivity and selectivity of the gas sensor to acetaldehyde gas. Mixing a metal catalyst with a metal oxide
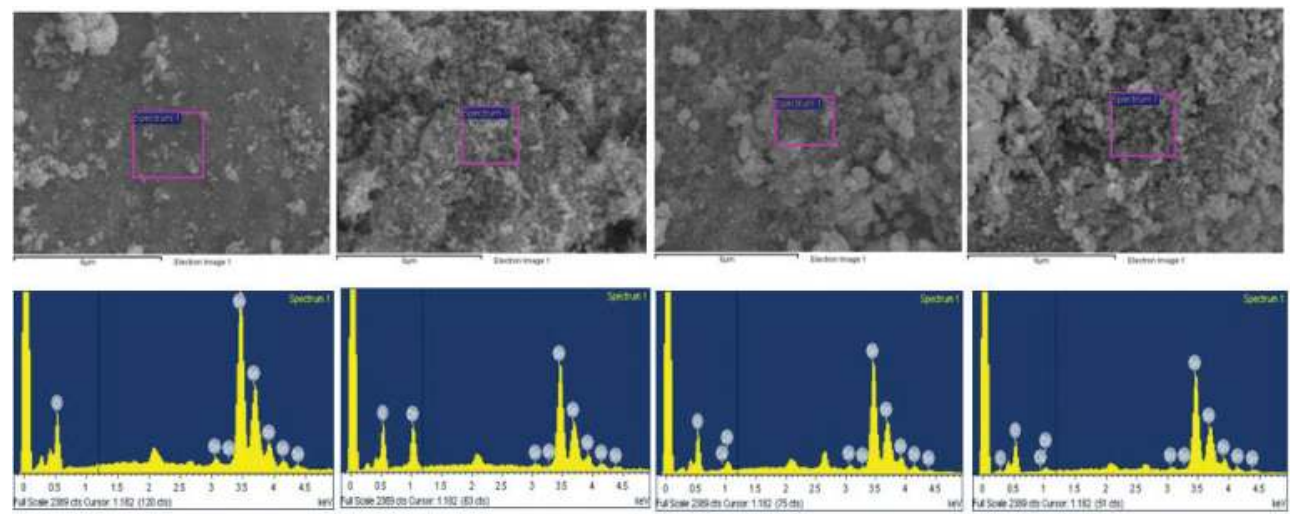

(a) $\mathrm{SnO}_{2}$

(b) $\mathrm{SnO}_{2} / \mathrm{ZnO}$

(c) $\mathrm{SnO}_{2} / \mathrm{ZnO} / \mathrm{Cu}$

(d) $\mathrm{SnO}_{2} / \mathrm{ZnO} / \mathrm{Cu}$ carbon black

Figure 11. SEM images and EDS results of the various sensor materials. 
induces an increase in the adsorption species caused by the activation of electrons. This affects the adsorption-desorption process, which results in an enhancement of electrical conductivity. To improve the effect of this catalytic reaction, the contacting area of metal catalysts with the sensor needs to be increased. Such a move has been found to greatly affect sensitivity, selectivity and operational temperature in terms of sensing the amount of gas [14].

Figure 14 depicts the sensing characteristics of sensor materials to acetaldehyde gas with various metal catalysts. The metal catalysts were added to $5 \mathrm{wt} \% \mathrm{SnO}_{2} / \mathrm{WO}_{3^{\prime}}$, which was used as main sensor material. As shown in Figure 14, the sensor material containing $1 \mathrm{wt} \%$ of $\mathrm{Ru}$ gives better sensitivity than those of other catalysts. This explains that $5 \mathrm{wt} \% \mathrm{SnO}_{2} /$ $\mathrm{WO}_{3}$ with a metal catalyst of $1 \mathrm{wt} \% \mathrm{Ru}$ shows better selectivity in oxidizing acetaldehyde gas

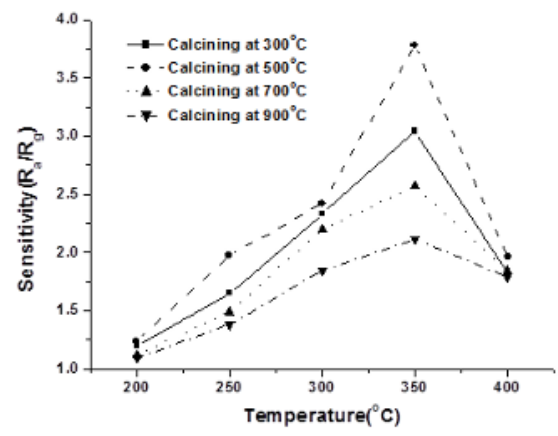

Figure 12. The sensitivity of $\mathrm{WO}_{3}$ thick films with various calcination temperatures for acetaldehyde gas (100 ppm) with different operating temperatures.

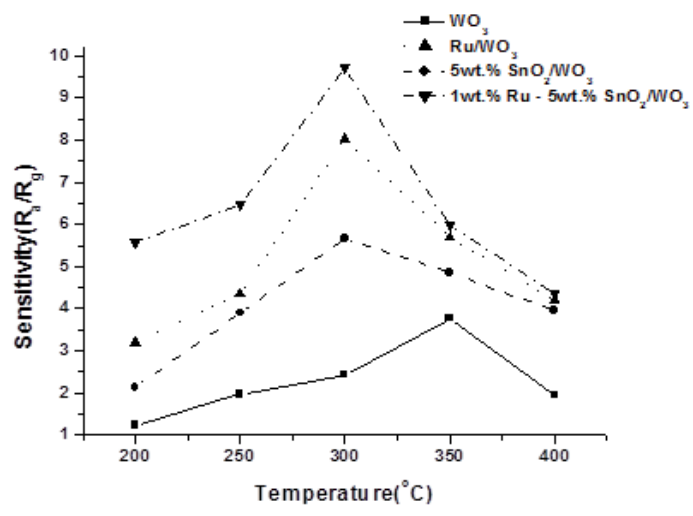

Figure 13. The sensitivity of the gas sensor for acetaldehyde gas (100 ppm) at various temperatures. 
than any other sensing materials. The reason we used $1 \mathrm{wt} \%$ concentration is that it gave the best sensitivity, that is, in the range of $0-1 \mathrm{wt} \%$, the sensitivity increases with elevated $\mathrm{Ru}$ concentrations. On the other hand, if the concentration exceeds $1 \mathrm{wt} \%$, there is a decrease in sensitivity. In this case, the Ru particles were not able to spread homogenously on the surface of the thick film due to the coagulation.

Figure 15 shows the results of the selectivity study of the sensing materials giving with the best selectivities toward acetaldehyde gas compared to various other volatile organic compounds. The sensitivity measurement of $1 \mathrm{wt} \% \mathrm{Ru} / 5 \mathrm{wt} \% \mathrm{SnO}_{2} / \mathrm{WO}_{3}$ gas sensor which showed the best sensitivity to acetaldehyde gas was performed within a concentration range of $100 \mathrm{ppm}$. The result showed that the sensitivity to acetaldehyde gas was much higher than other gases. It means that the sensing material of $1 \mathrm{wt} \% \mathrm{Ru} / 5 \mathrm{wt} \% \mathrm{SnO}_{2} / \mathrm{WO}_{3}$ works better for acetaldehyde gas in decomposing and activating reaction than for other VOC gases.

\subsection{Sensing characteristics to $\mathrm{H}_{2} \mathrm{~S}$ gas}

The sensing response of $\mathrm{WO}_{3} / \mathrm{SnO}_{2}$ was investigated for different type of sensor materials where the amounts of metal catalyst added were varied. The kinds of catalyst were selected to give a good response and selectivity to $\mathrm{H}_{2} \mathrm{~S}$ gas. In general, metal catalyst mixed with metal oxide helps to transfer electrons smoothly and increases the number of absorbed species in the absorption process, which lead to the change of electric conductivity on the sensor material. It has also been known that increasing the contact area affects the catalyst to enhance the response, selectivity and operating temperature of the sensor [15].

Figure 16 shows the response of hydrogen sulfide across different metal catalysts. Various metal catalysts were added to the basic sensor material composed of $10 \mathrm{wt} \% \mathrm{WO}_{3} / \mathrm{SnO}_{2}$. As shown in Figure 16, the sensor material with added $1 \mathrm{wt} \%$ Ru compared to other metal catalysts, and the operating temperature was $200^{\circ} \mathrm{C}$, which represented a reduction of $50^{\circ} \mathrm{C}$. This meant that $1 \mathrm{wt} \% \mathrm{Ru} / 10 \mathrm{wt} \% \mathrm{WO}_{3} / \mathrm{SnO}_{2}$ sensor material oxidized hydrogen sulfide better than other sensor materials and also showed better selectivity.

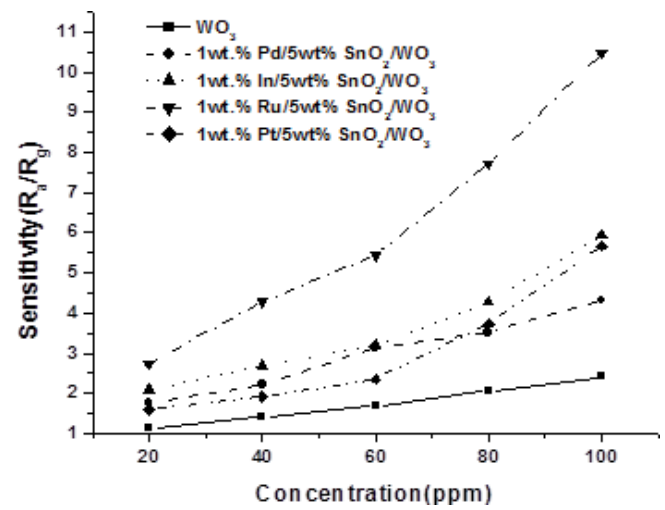

Figure 14. Sensitivity of catalyst $/ 5 \mathrm{wt} \% \mathrm{SnO}_{2} / \mathrm{WO}_{3}$ to various concentration of acetaldehyde gas at $300^{\circ} \mathrm{C}$. 


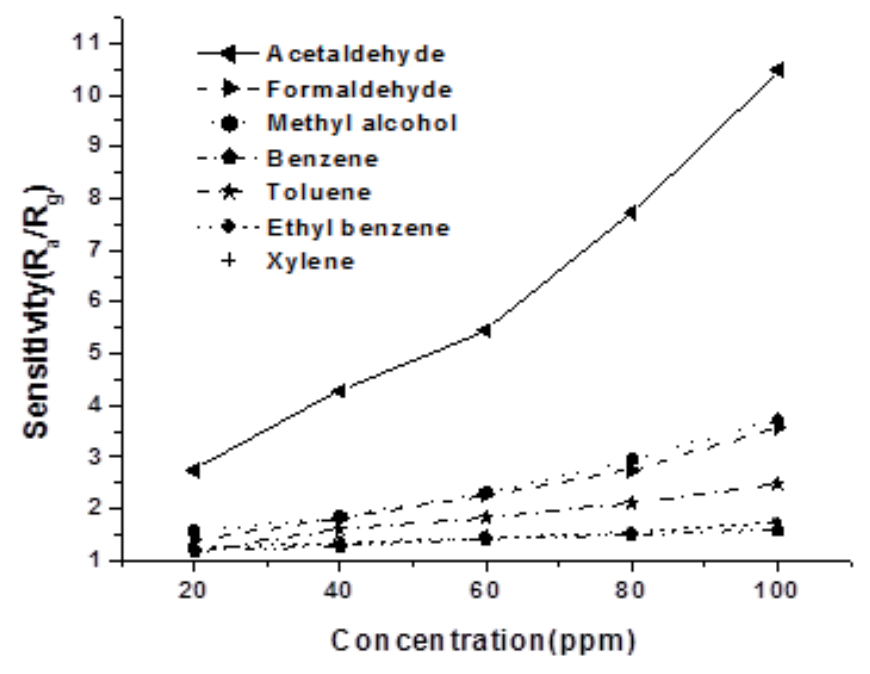

Figure 15. The sensitivity of $1 \mathrm{wt} \% \mathrm{Ru} / 5 \mathrm{wt} \% \mathrm{SnO}_{2} / \mathrm{WO}_{3}$ to various gases $(100 \mathrm{ppm})$ at $300^{\circ} \mathrm{C}$.

Figure 17 shows the sensing response of $\mathrm{H}_{2} \mathrm{~S}$ gas for the samples of various amount of metal catalysts added to find the optimal condition. For the main sample of $10 \mathrm{wt} \% \mathrm{WO}_{3} / \mathrm{SnO}_{2}$, the sensing response was examined by varying the amount of Ru catalyst added in the range of $0.5-5.0 \mathrm{wt} \%$, and it was found to be the best for the case of $1 \mathrm{wt} \%$ Ru addition. When the quantity of catalyst was below $1 \mathrm{wt} \%$, it is not sufficient to activate the reaction. While the quantity of catalyst was above $1 \mathrm{wt} \%$, the Ru particles aggregated itself and changed the characteristics of sensor material which did not further improve responses.

Figure 18 shows the response comparing the changes in different concentration levels of $100 \mathrm{ppm}$ of hydrogen sulfide at $200^{\circ} \mathrm{C}$ when $\mathrm{SnO}_{2}$ was mixed with $10 \mathrm{wt} \% \mathrm{WO}_{3}+1 \%$ Ru. Finally, the sensor material of $1 \mathrm{wt} \% \mathrm{Ru} / 10 \mathrm{wt} \% \mathrm{WO}_{3} / \mathrm{SnO}_{2}$ showed the best response characteristics.

Figure 19 presents the selectivity results of various gases based on the sensor material showing the best sensitivity for $\mathrm{H}_{2} \mathrm{~S}$ gas. The sensor prepared with the material of $1 \mathrm{wt} \% \mathrm{Ru} / 10$ $\mathrm{wt} \% \mathrm{WO}_{3} / \mathrm{SnO}_{2}$ showed the best sensitivity and was tested its sensitivities to various gases at an operating temperature of $200^{\circ} \mathrm{C}$ and the concentration range of $20-100 \mathrm{ppm}$. As a result, the sensor showed better response to $\mathrm{H}_{2} \mathrm{~S}$ gas than to other gases. Therefore, it is known that $1 \mathrm{wt} \% \mathrm{Ru} / 10 \mathrm{wt} \% \mathrm{WO}_{3} / \mathrm{SnO}_{2}$ adsorbs $\mathrm{H}_{2} \mathrm{~S}$ gas well and enhances the catalytic reaction to improve the selectivity.

\subsection{Response characteristics to toluene gas}

Carbon black is a material made by covalent bonding of carbon. It is known that carbon black has good electric conductivity and good thermal conductivity. There is existing literature 


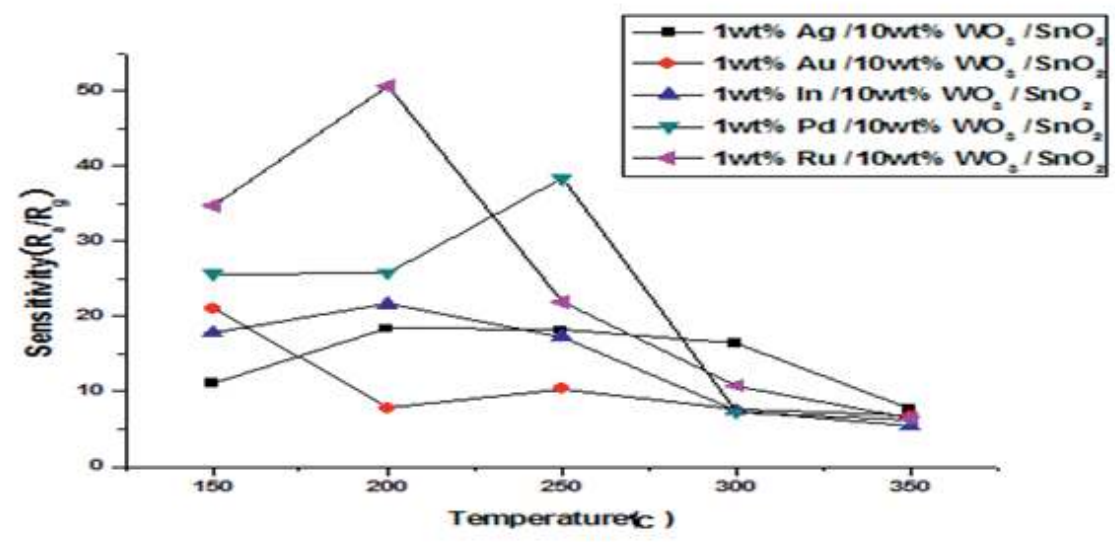

Figure 16. Response with catalysts $/ 10 \mathrm{wt} \% \mathrm{WO}_{3} / \mathrm{SnO}_{2}$ to the hydrogen sulfide gas $(100 \mathrm{ppm})$ at different operating temperatures.

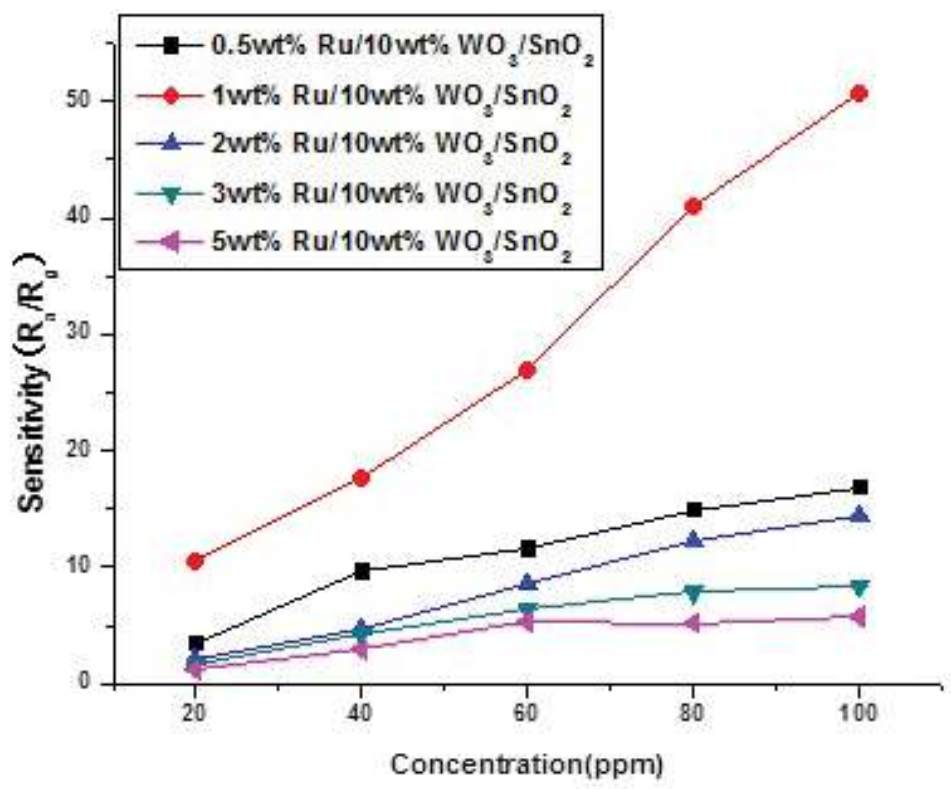

Figure 17. Sensitivity with the catalyst $/ \mathrm{WO}_{3} / \mathrm{SnO}_{2}$ to the various concentrations of hydrogen sulfide gas at $200^{\circ} \mathrm{C}$.

study that reported the addition of carbon black on sensor material to decrease sensor operation temperature [16-18]. In this study, carbon black is added to sensor material to decrease operation temperature and increase the sensitivity of the sensor. Figure $\mathbf{2 0}$ is the sensitivity on 100 ppm toluene gas depends on carbon black added quantity. As seen in the figure, the 


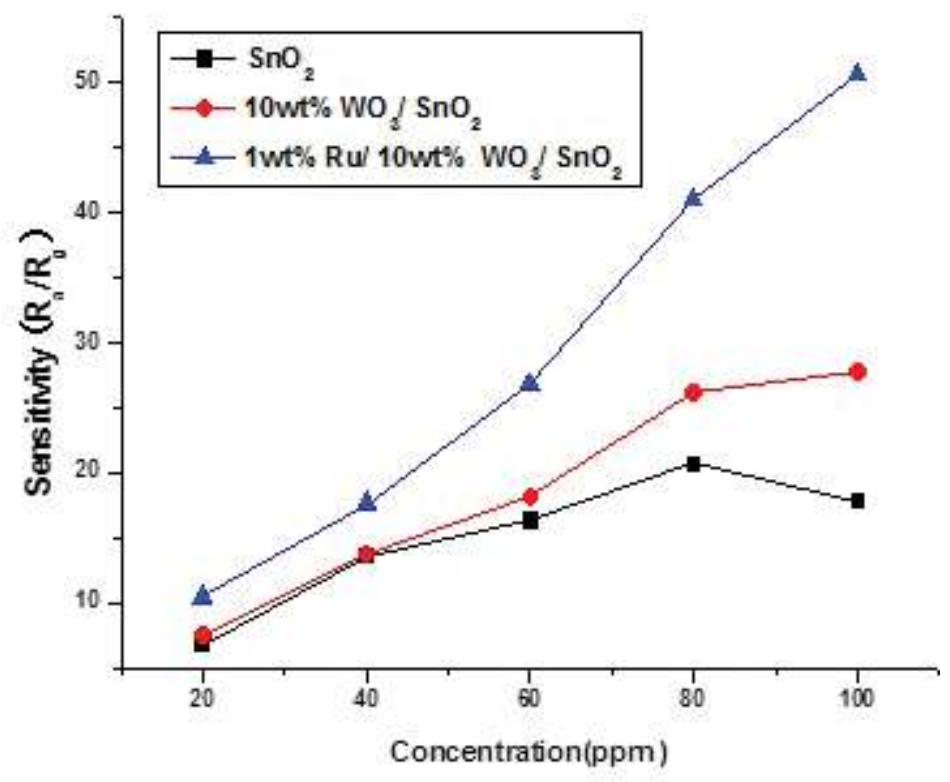

Figure 18. The sensitivity of $1 \mathrm{wt} \% \mathrm{Ru} / 10 \mathrm{wt} \% \mathrm{WO}_{3} / \mathrm{SnO}_{2}$ from $20 \mathrm{ppm}$ to $100 \mathrm{ppm}$ of hydrogen sulfide gas at $200^{\circ} \mathrm{C}$.

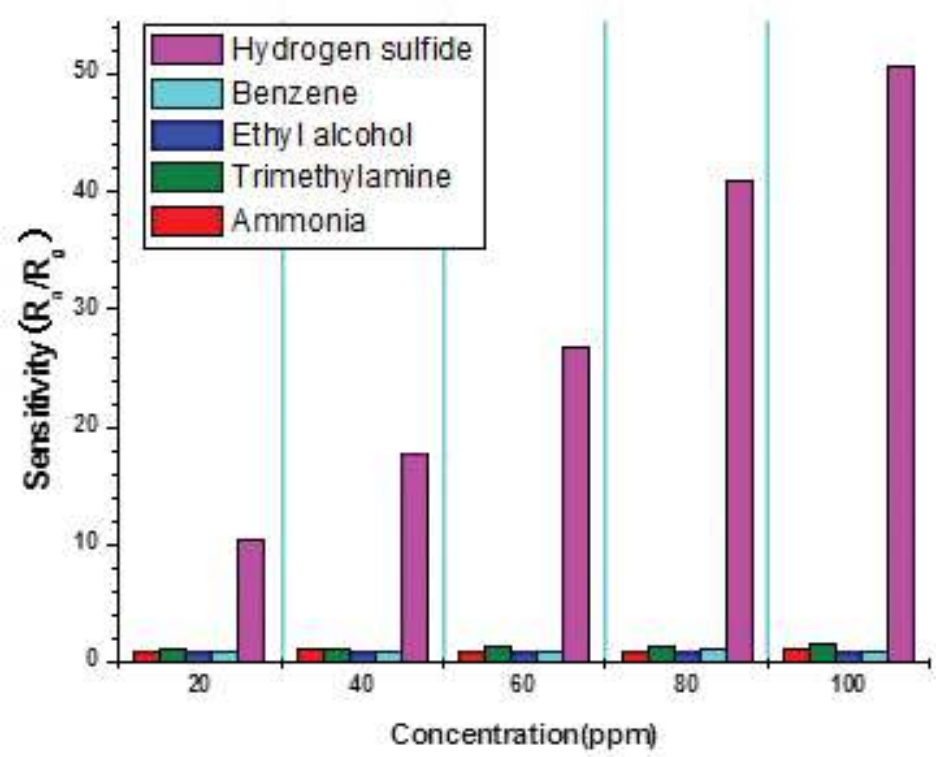

Figure 19. Sensitivity of $1 \mathrm{wt} \% \mathrm{Ru} / 10 \mathrm{wt} \% \mathrm{WO}_{3} / \mathrm{SnO}_{2}$ to the various concentrations of various gases at $200^{\circ} \mathrm{C}$. 


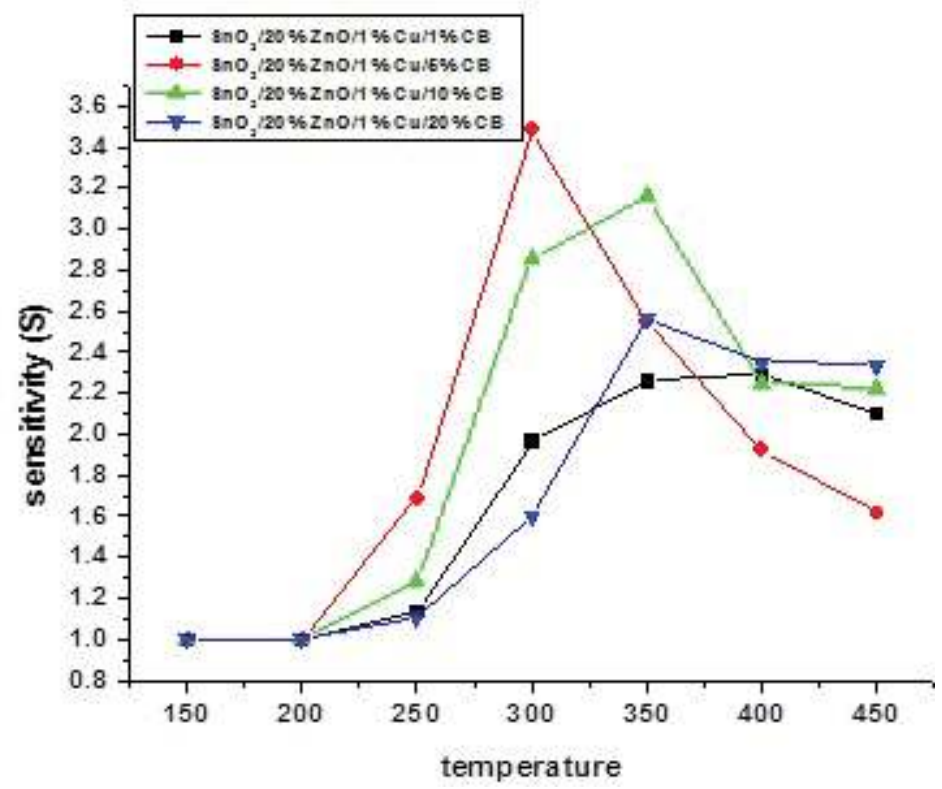

Figure 20. Sensitivity of sensors with various contents of carbon black to the toluene gas (100 ppm) at various temperatures.

sensitivity of sensor fabricated with material added of $5 \mathrm{wt}$.\% carbon black of $\mathrm{SnO}_{2}$ has better sensitivity and $50^{\circ} \mathrm{C}$ lower operation temperature compared to sensors fabricated with material added of different $w \mathrm{t} \%$ of carbon black. The reason is believed that the sensor sensitivity and operation temperature decreased by the increase in heat dispersion in sensor material when carbon black was added.

Figure 21 is the sensitivity measurement on $100 \mathrm{ppm}$ toluene gas using a sensor fabricated with different components such as $\mathrm{SnO}_{2}, \quad \mathrm{SnO}_{2} / 20 \% \mathrm{ZnO}, \quad \mathrm{SnO}_{2} / 20 \% \mathrm{ZnO} / 1 \% \mathrm{Cu}$ and $\mathrm{SnO}_{2} / 20 \% \mathrm{ZnO} / 1 \% \mathrm{Cu} / 5 \%$ carbon black. As seen in the figure, the sensor fabricated with $\mathrm{SnO}_{2} / 20 \% \mathrm{ZnO} / 1 \% \mathrm{Cu} / 5 \%$ carbon black has better sensitivity and lower operation temperature compared to sensors produced with other three materials.

Figure 22 is the sensitivity measurement on 1-20 ppm low concentration toluene gas using a sensor made of $\mathrm{SnO}_{2} / 20 \% \mathrm{ZnO} / 1 \% \mathrm{Cu} / 5 \%$ carbon black, which showed the best sensitivity in this study. This sensor showed a linear increase in sensitivity at a concentration of $20 \mathrm{ppm}$ or less in general.

Figure 23 is the selectivity on various volatile gases of the sensor fabricated with $\mathrm{SnO}_{2} /$ $20 \% \mathrm{ZnO} / 1 \% \mathrm{Cu} / 5 \%$ carbon black, which showed the best sensitivity on toluene gas in this study. Sensitivity was measured on various gases at $300^{\circ} \mathrm{C}$ operation temperature and 10-100 ppm concentration range. The result suggested that the sensor had the best sensitivity on toluene gas compared to the sensitivity to other gases. There was some interference effect 


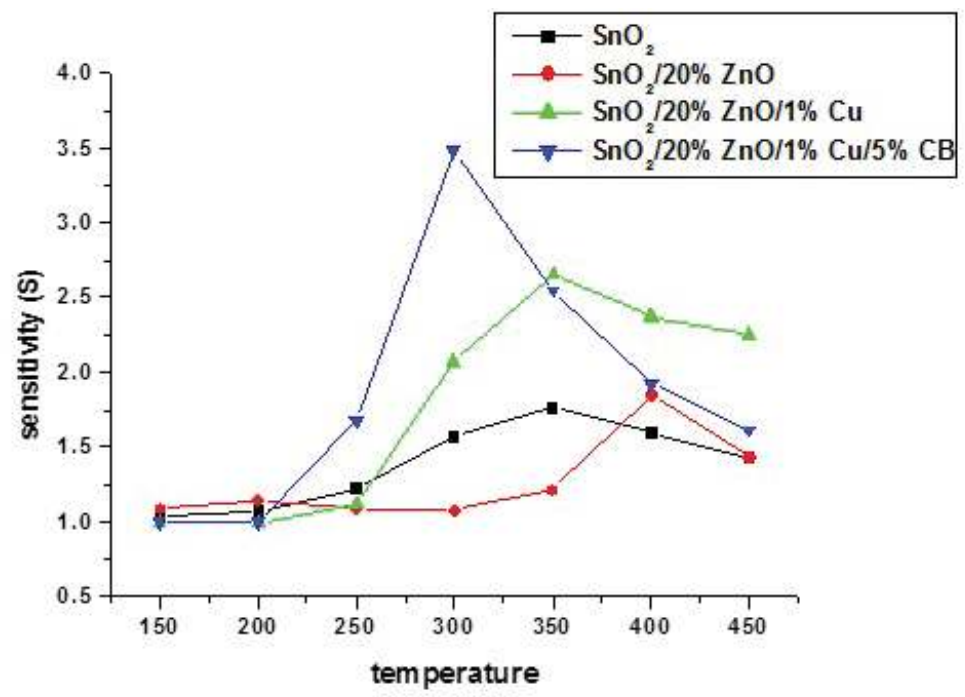

Figure 21. Sensitivity of the $\mathrm{SnO}_{2} / 20 \% \mathrm{ZnO} / 1 \% \mathrm{Cu} / 5 \%$ carbon black sensor for toluene gas (100 ppm) to the various temperatures.

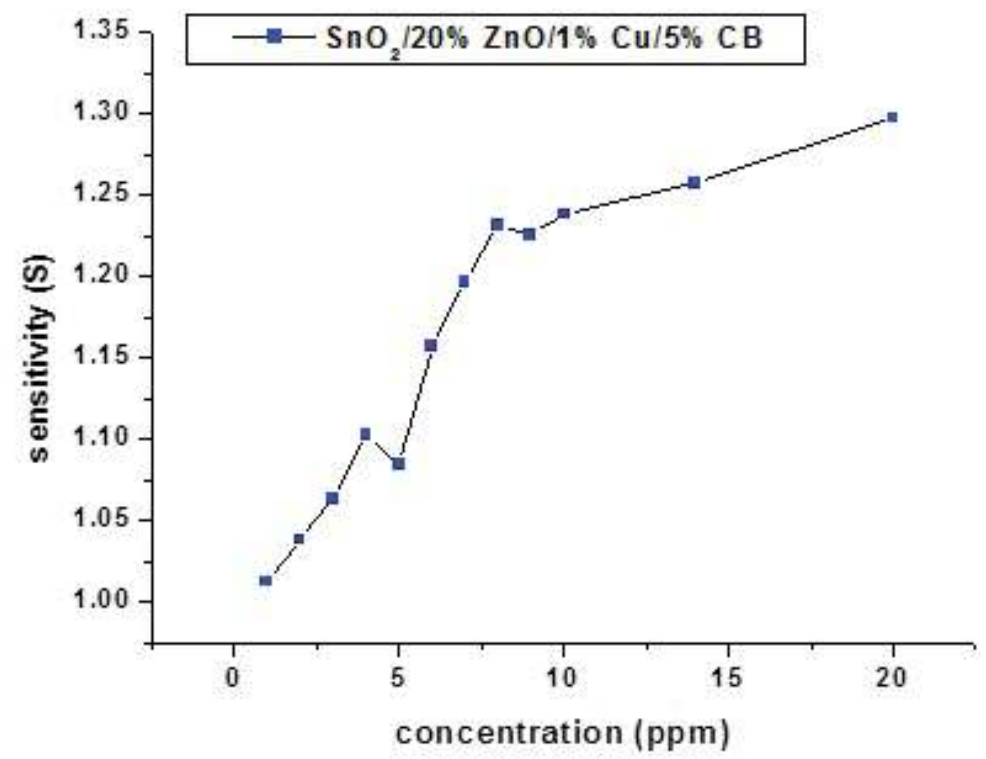

Figure 22. Sensitivity of $\mathrm{SnO}_{2} / 20 \% \mathrm{ZnO} / 1 \% \mathrm{Cu} / 5 \%$ carbon black sensor from 1 to $20 \mathrm{ppm}$ of toluene gas at $300^{\circ} \mathrm{C}$. 


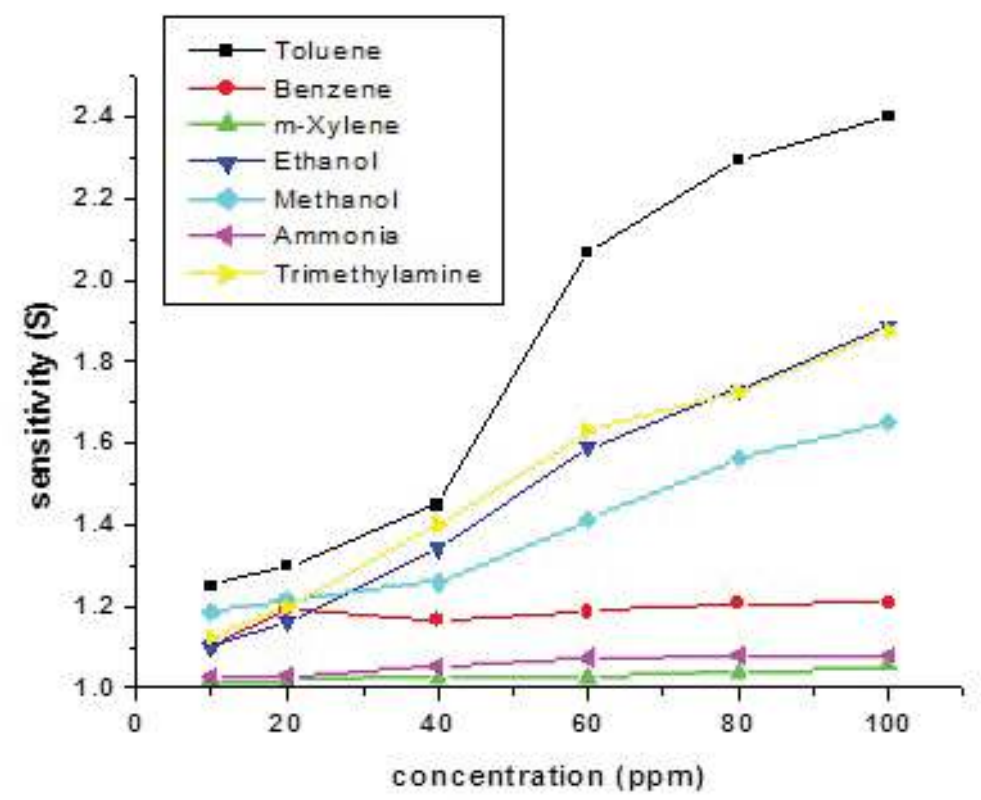

Figure 23. Sensitivity of $\mathrm{SnO}_{2} / 20 \% \mathrm{ZnO} / 1 \% \mathrm{Cu} / 5 \%$ carbon black to the various gases at $300^{\circ} \mathrm{C}$.

from ethanol and trimethylamine gas; however, interference effect from other volatile gases was not so significant. A sensor fabricated with $\mathrm{SnO}_{2} / 20 \% \mathrm{ZnO} / 1 \% \mathrm{Cu} / 5 \%$ carbon black has better selectivity on toluene gas, because it decomposes more toluene gas and activates more reaction compared to other volatile gas.

\section{Conclusion}

Semiconductor metal oxide gas sensors can be used for diverse applications, ranging from equipment to monitor environmental and occupational safety to facilitating quality assurance through novel measurement. The nature of the gas-sensitive material and the concentration of the target gas (usually a few ppb-ppm) will determine the measuring range and limitations of the device.

In this study, the metal oxide gas sensor was fabricated with $\mathrm{SnO}_{2}$ and $\mathrm{WO}_{3}$ as the basic substances added to the metal oxide $\left(\mathrm{SnO}_{2}, \mathrm{WO}_{3^{\prime}}\right.$ and $\left.\mathrm{ZnO}\right)$ and various metal catalysts to detect the toxic gas. By changing the added amount and types of metal oxide and catalysts, this study investigated the sensitivity, operating temperature and recovery properties for the toxic gas.

(1) The sensing characteristics of the fabricated gas sensors added with catalysts and metal oxides to $\mathrm{SnO}_{2}$ tend to rely on the operating temperature, calcination temperature and the kind and composition of the catalyst and metal oxide. 
(2) The optimal conditions for the fabrication of the sensor material for detecting acetaldehyde gas were known to be $300^{\circ} \mathrm{C}$ as an operation temperature, $500^{\circ} \mathrm{C}$ as a calcination temperature, $20 \mu \mathrm{m}$ as a film thickness and ethylene glycol as a binder. The best sensitivity, selectivity and response-recovery characteristics were achieved when $1 \mathrm{wt} \% \mathrm{Ru} / 5$ $\mathrm{wt} \% \mathrm{SnO}_{2}$ was added to the $\mathrm{WO}_{3}$ sensing material.

(3) The sensing characteristics of hydrogen sulfide gas sensor made by adding catalyst and metal oxide to $\mathrm{SnO}_{2}$ tend to rely on the operating temperature, calcination temperature and kind and composition of catalyst and metal oxide. The ideal condition for the sensor material to detect $\mathrm{H}_{2} \mathrm{~S}$ gas is temperatures of $200^{\circ} \mathrm{C}$ for operation and $600^{\circ} \mathrm{C}$ for calcination, and the sample of $\mathrm{SnO}_{2}$ added with $10 \mathrm{wt} \% \mathrm{WO}_{3}$ and $1 \mathrm{wt} \% \mathrm{Ru}$.

(4) The optimum conditions for the toluene gas detection sensor are an operating temperature of $300^{\circ} \mathrm{C}$ with added metal catalyst $\mathrm{Cu}$ and carbon black. The best sensitivity and highest selectivity were achieved with $20 \% \mathrm{ZnO}, 1 \% \mathrm{Cu}$ and $5 \%$ carbon black, in terms of $\mathrm{wt} \%$ to $\mathrm{SnO}_{2}$ added to $\mathrm{SnO}_{2}$ by impregnation.

\section{Acknowledgements}

This research was financially supported by the Ministry of Education (MOE) and National Research Foundation of Korea (NRF) through the Human Resource Training Project for Regional Innovation (no. 2015H1C1A1035858).

\section{Author details}

Chang-Seop Lee* and Yong Jae Kim

*Address all correspondence to: surfkm@kmu.ac.kr

Department of Chemistry, Keimyung University, Daegu, South Korea

\section{References}

[1] Wark K, Warner CF. Air Pollution: Its Origin and Control. New York: Haper Collins; 1981

[2] Noordally E, Richmond JR, Tahir SF. Destruction of volatile organic compounds by catalytic oxidation. Catalysis Today. 1993;17(1-2):359-366

[3] Hodgson AT, Faulkner D, Sullivan DP, DiBartolomeo DL, Russell ML, Fisk WJ. Effect of outside air ventilation rate on volatile organic compound concentrations in a call center. Atmospheric Environment. 2003;37(39-40):5517-5527 
[4] Min BK, Choi SD. Development of methane gas sensor by various powder preparation methods. Journal of the Korean Ceramic Society. 1999;5(2):125-130

[5] Lim CB, Oh SJ. Microstructure evolution and gas sensitivities of Pd-doped $\mathrm{SnO}_{2}$-based sensor prepared by three different catalyst-addition processes. Sensors and Actuators B: Chemical. 1996;30(3):223-231

[6] Yoo DJ, Tamaki J, Miura N, Yamazoe N, Park SJ. Effect of film thickness on gas sensing behavior of thin-film-type gas sensor. Korean Journal of Materials Research. 1996;6(7):716-722

[7] Acosta DR, Zironi EP, Montoya E, Estrada W. About the structural, optical and electrical properties of $\mathrm{SnO}_{2}$ films produced by spray pyrolysis from solutions with low and high contents of fluorine. Thin Solid Films. 1996;288(1-2):1-7

[8] Serrini P, Briois V, Horrillo MC, Travers A, Manes L. Chemical composition and crystalline structure of $\mathrm{SnO}_{2}$ thin films used as gas sensors. Thin solid Films. 1997;304(1-2):113-122

[9] Qi Q, Zhang T, Liu L, Zheng X. Improved $\mathrm{NH}_{3} \mathrm{C}_{2} \mathrm{H}_{5} \mathrm{OH}$, and $\mathrm{CH}_{3} \mathrm{COCH}_{3}$ sensing properties of $\mathrm{SnO}_{2}$ nanofibers by adding block copolymer P123. Sensors and Actuators B. 2009;141(1):174-178

[10] Zeng Y, Zhang T, Wang L, Kang M, Fan H, Wang R, He Y. Enhanced toluene sensing characteristics of $\mathrm{TiO}_{2}$-doped flowerlike $\mathrm{ZnO}$ nanostructures. Sensors and Actuators B. 2009;140(1):73-78

[11] Song X, Zhang D, Fan M. A novel toluene sensor based on $\mathrm{ZnO}-\mathrm{SnO}_{2}$ nanofiber web. Applied Surface Science. 2009;255(16):7343-7347

[12] Kawahara A, Katsuki H, Egashira M. Fabrication of semiconductor oxide thick films by slide-off transfer printing and their $\mathrm{NO}_{2}$-sensing properties. Sensors and Actuators B. 1998;49(3):273-278

[13] Khadayate RS, Sali JV, Patil PP. Acetone vapor sensing properties of screen printed $\mathrm{WO}_{3}$ thick films. Talanta. 2007;72(3):1077-1081

[14] Xu C, Kurokawa J, Miura N, Yamazoe N. Stabilization of $\mathrm{SnO}_{2}$ ultrafine particles by additives. Journal of Materials Science. 1992;27(4):963-971

[15] Dean JA. Lange's Handbook of Chemistry. 12th ed. New York: McGraw Hill; 1979. pp. $10-54$

[16] Yamazoe N, Kurokawa Y, Seiyama T. Effects of additives on semiconductor gas sensors. Sensors and Actuators. 1983;4:283-289

[17] Yamazoe N. New approaches for improving semiconductor gas sensors. Sensors and Actuators B: Chemical. 1991;5(1-4):7-19

[18] Yamazoe N, Miura N. Some basic aspects of semiconductor gas sensors. Chemical Sensor Technology. 1992;4:19-42 
